\title{
Effect of Growth Hormone (hGH) Replacement Therapy on Physical Work Capacity and Cardiac and Pulmonary Function in Patients with hGH Deficiency Acquired in Adulthood
}

\author{
RALF NASS, RUDOLF M. HUBER, VOLKER KLAUSS, OTTO A. MÜLLER, \\ JOCHEN SCHOPOHL, AND CHRISTIAN J. STRASBURGER \\ Medical Clinic, Innenstadt University Hospital, Ludwig-Maximilians-Universität, Munich, Germany
}

\begin{abstract}
The effects of 6 months of replacement therapy with recombinant human $\mathrm{GH}(\mathrm{hGH})$ on physical work capacity and cardiac structure and function were investigated in 20 patients with hGH deficiency of adult onset in a double blind, placebo-controlled trial. The GH dose of $12.5 \mu \mathrm{g} / \mathrm{kg} \mathrm{BW}$ was self-administered daily sc. Oxygen consumption $\left(\mathrm{VO}_{2}\right), \mathrm{CO}_{2}$ production, and ventilatory volumes were measured during exercise on a bicycle spiroergometer. M-Mode echocardiography was performed using standard techniques. The $\mathrm{VO}_{2}$ max data, expressed per $\mathrm{kg} \mathrm{BW}(\mathrm{mL} / \mathrm{min} \cdot \mathrm{kg} \mathrm{BW})$ showed a significant increase from $23.2 \pm 2.4$ to $30.0 \pm 2.3(P<0.01)$ in the hGH-treated group, whereas the $\mathrm{VO}_{2}$ max data, expressed per lean body mass (milliliters per $\mathrm{min} / \mathrm{kg}$ lean body mass) did not change significantly in either group. Maximal $\mathrm{O}_{2}$ pulse (milliliters per beat) increased significantly from $15.2 \pm 5.6$ to $19.6 \pm 3.3 \mathrm{~mL} /$ beat $(P<0.01)$, but remained constant in the placebo group. The maximal power output (watts \pm $\mathrm{SE})$ increased significantly $(P<0.01)$ from $192.5 \pm 13.5$ to $227.5 \pm 11.5$
\end{abstract}

in the hGH-treated group, but remained constant in the placebo group. Cardiac structure (left ventricular posterior wall, interventricular septum thickness, left ventricular mass, left ventricular endsystolic dimension, and left ventricular end-diastolic dimension) as well as echocardiographically assessed cardiac function did not change significantly after 6 months of treatment in either group. We conclude that hGH replacement in hGH-deficient adults improves oxygen uptake and exercise capacity. These improvements in pulmonary parameters might be due to an increase in respiratory muscle strength and partly to the changes in muscle volume per se observed during hGH replacement therapy. Furthermore, an increased cardiac output might contribute to the improvement in exercise performance during hGH treatment.

According to our data, hGH replacement therapy leads to an improvement of exercise capacity and maximal oxygen uptake, but has no significant effect on cardiac structure. $(J$ Clin Endocrinol Metab 80: $552-557,1995$ )
G H IS SECRETED from the anterior lobe of the pituitary gland throughout life, although the amounts released gradually decline with increasing age $(1,2)$. The physiological importance of sustained GH secretion in adulthood is still poorly understood. In children with GII deficiency, treatment with $\mathrm{GH}$, besides promotion of longitudinal bone growth, has important effects on body composition $(3,4)$. In adults, GH deficiency is associated with a reduction in lean body mass and an increase in body fat mass (5). Furthermore, adults with panhypopituitarism often do not feel well despite adequate hormone replacement therapy with thyroid hormone and adrenal and sex steroids, but not GH. In a recent study, Bengtsson and co-workers (6) showed that human $\mathrm{GH}(\mathrm{hGH})$ replacement therapy in hGH-deficient adults results in marked alterations in body composition, especially a considerable loss of body fat and an increase in muscle volume. Whether these changes observed during hGH therapy will cause functional improvements and, therefore, will justify the cost (7) of the replacement therapy is a matter of controversial discussion. We performed a double blind, pla-

Received March 1, 1994. Received September 15, 1994. Accepted October 31, 1994.

Address all correspondence and requests for reprints to: Dr. Christian J. Strasburger, Division of Neuroendocrinology, Medical Clinic, Innenstadt University Hospital, Ziemssenstrasse. 1, 80.336 Munich, Germany.

* This work was supported by a grant from Eli Lilly International Corp. cebo-controlled trial of hGH replacement therapy in 20 patients suffering from GH deficiency acquired in adulthood. The aim of our study was to evaluate whether the alterations in body composition observed during hGH replacement therapy lead to improved exercise capacity and power output and, therefore, are beneficial for our patients in performing their daily tasks. We report the effects of hGH treatment on pulmonary parameters and physical work capacity in adults with GH deficiency after a 6-month treatment period.

A recent study (8) suggests that GH replacement therapy in GH-deficient adults might affect cardiac function and structure. As cardiac function is an important determinant of exercise performance, we additionally investigated the effects of hGH on these cardiac parameters in our patients.

\section{Methods}

Twenty patients, ranging in age from $27-60 \mathrm{yr}$ ( 15 males and 5 females), with a mean body mass index of $30.2 \mathrm{~kg} / \mathrm{m}^{2}$ participated in the study. All patients had acquired GH deficiency during adulthood, generally as a consequence of treatment for pituitary tumors, and received stable hormone replacement with corticosteroid, $T_{4}$, and gonadal steroids for at least 12 months before entry into the trial (Table 1). With the exception of 1 male subject in the hGH-treated group, who did not require gonadal steroid replacement therapy, all of our patients received adequate and constant gonadal steroid replacement therapy for 12 months before and during the trial. To minimize the influence of different gonadal steroid levels, all of the female patients were studied 
TABLE 1. Clinical details of subjects

\begin{tabular}{lcc}
\hline & $\begin{array}{c}\text { Placebo group } \\
(\mathrm{n}=10)\end{array}$ & $\begin{array}{c}\text { Verum group } \\
(\mathrm{n}=10)\end{array}$ \\
\hline Mean age (yr) & 45.1 & 44.2 \\
Range (yr) & $27-60$ & $28-60$ \\
Sex (M/F) & $6 / 4$ & $9 / 1$ \\
Known duration of GH & 8 & 6 \\
$\quad$ deficiency (yr) & & \\
Chromophobe adenoma & 2 & 4 \\
Prolactinoma & 1 & 1 \\
Craniopharyngioma & 2 & 2 \\
Others & \\
Ht $(\mathrm{cm})$ & 5 & 3 \\
Wt $(\mathrm{kg})$ & $170.2 \pm 3.3$ & $172.6 \pm 2.6$ \\
BMI $\left(\mathrm{kg} / \mathrm{m}^{2}\right)$ & $86.3 \pm 5.4$ & $90.8 \pm 3.6$ \\
Basal IGF-I (ng/mL) & $29.9 \pm 0.5$ & $30.4 \pm 0.5$ \\
\hline
\end{tabular}

Data are presented as the mean $\pm \mathrm{SE}$.

${ }^{a}$ Others include one Sheehan syndrome, one empty sella syndrome, one Histiocytosis $\mathrm{X}$ and traumatic brain injuries.

during the first half of an artificial menstrual cycle. Male patients were studied in the second week of a 3-week dose interval.

Smoking habits (only three of the patients in the verum group were occasional smokers of fewer than five cigarettes per day; none of the placebo group was a smoker) were unchanged during the trial and played a minor role in our patients. The nature of the trial was explained to the patients, and their written informed consents were obtained. The study protocol was approved by the local ethics committee. Entry criteria included insulin-like growth factor (IGF-I) levels [measured by the method of Blum et al. (9)] below $120 \mathrm{ng} / \mathrm{mL}$ and a hGH stimulation test (insulin tolerance test or arginine infusion $(30 \mathrm{~g})$ in the case of contraindications to insulin tolerance test), with a peak GH response below 2 $\mathrm{ng} / \mathrm{mL}$. Biosynthetic hGH was given in the double blind, placebocontrolled trial over a treatment period of 6 months. GH was selfadministered sc daily before bedtime in a dose of $12.5 \mu \mathrm{g} / \mathrm{kg} \mathrm{BW}$. Study material, labeled identically for $\mathrm{hCH}$ - and placebo-containing vials, was provided by Eli Lilly Co. (Erl Wood, United Kingdom). Randomization of the 20 patients to study numbers was performed by Eli Lilly Co. Exercise tests were performed at baseline and after 6 months of treatment. The tests were performed in the morning, and standard replacement therapy was taken in the morning of the visit before the tests started. Venous blood samples were taken after an overnight fast.

After all patients had completed the 6-month, double blind, placebocontrolled period, IGF-I levels were analyzed, and those 10 patients showing a marked increase in IGF-I levels during treatment were concluded to have received $\mathrm{GH}$ (verum), whereas those showing no alteration in IGF-I levels were concluded to have received placebo. The replacement trial is being continued in a single blinded manner, i.e. the patients are still blinded.

\section{Exercise test}

Height and weight was measured on the day of the visit. Patients were positioned on a cycle ergometer in a semirecumbent position and requested to pedal with a frequency of $40-50 \mathrm{rpm}$. Clips were fitted, and the seat height was adjusted. Before starting the measurements, the patients had a resting period for steady state ventilation. $\mathrm{O}_{2}$ consumption $\left(\mathrm{VO}_{2}\right), \mathrm{CO}_{2}$ production $\left(\mathrm{VCO}_{2}\right)$ from a mixing chamber, and ventilatory volumes as well as heart frequency and blood pressure were measured with an Ergotest machine (Fa. Jäger, Würzburg, Hochberg, Germany). This machine uses infrared $\mathrm{CO}_{2}$ and paramagnetic $\mathrm{O}_{2}$ analyzers and a turbine pneumotachygraph, recording every $15 \mathrm{~s}$. Calibration against standard gases $\left(16 \% \mathrm{O}_{2}\right.$ and $\left.4 \% \mathrm{CO}_{2}\right)$, volume $(1000 \mathrm{~mL})$, operating temperature, and barometric pressure was performed immediately before each test. Data analyses were performed with the J-Labsystem, using a RSX-DEC System (Fa. Jäger). The work rate was set at 50 watts for the first minute and was increased by 25 watts every minute until an exhaustion-limited maximum was reached. Heart rate was recorded by surface electrocardiography during the entire exercise period. Blood pressure was measured in 1-min intervals. $\mathrm{O}_{2}$ pulse was defined as $\mathrm{VO}_{2}$ max divided by heart rate and reflects an approximation of stroke volume, under the assumption that arterio-venous $\mathrm{O}_{2}$ content differs little between individuals at maximal exercise.

The ventilatory anaerobic threshold was calculated from a diagram of $\mathrm{VO}_{2} v s$. $\mathrm{VCO}_{2}$ and minute ventilation. Manual curve fitting was performed by one observer blinded to the origin of the graph being assessed.

Measurements of lean body mass were performed with a total body potassium-40 $\gamma$-counter. The measurements of total body potassium were compared with predicted normal values according to sex, age, height, and weight (10). Lean body mass was calculated on the assumption that there is $60 \mathrm{mmol}$ potassium $/ \mathrm{kg}$ lean body mass in women and $66 \mathrm{mmol} / \mathrm{kg}$ lean body mass in men (11).

\section{Echocardiography}

Transthoracic echocardiograms were obtained with subjects in the left lateral decubitus position. All echocardiograms were performed by the same investigator, blinded to the treatment code, using a commercially available electronic sector scanner (SSH 40, Toshiba Medical Systems Europe, Delft, The Netherlands) with a 2.5-megahertz phased array transducer. Two-dimensional guided $\mathrm{M}$-mode recordings were obtained from the parasternal window. From the M-mode recording, the following measurements were made using American Society of Echocardiography standards (12): interventricular septal thickness, posterior wall thickness, left ventricular end-diastolic dimension (LVEDD), and left ventricular end-systolic dimension (LVESD). Left ventricular mass (LVM) was calculated from the M-mode measurements using the formula modified by Devereux et al. (13) and was indexed to body surface area. The echocardiographic examination and the exercise test were performed on the same day.

\section{Statistics}

Results were expressed as the mean \pm SE. Statistical analysis within each of the two treatment groups was performed with a paired Wilcoxon test; $P<0.05$ was considered significant. Differences in the mean values between both groups at baseline were compared by Mann-Whitney $U$ test; $P<0.05$ was again considered significant. The interassay coefficients of variation for the response variables for IGF-I measurement, ventilation parameters, cardiac parameters, and lean body mass measurement were all below $10 \%$.

\section{Results}

\section{Effects of treatment with $h G H$}

Fasting serum concentrations of IGF-I and lean body mass. IGF-I levels ( $\pm \mathrm{SE})$, as measured by the method of Blum et al. (9), increased from $62.4 \pm 11.6$ to $303.1 \pm 48.9 \mathrm{ng} / \mathrm{mL}(P<0.005)$ in 10 of our patients, but remained constant in 10 others (from $55.8 \pm 10.4$ to $58.8 \pm 9.5 \mathrm{ng} / \mathrm{mL}$ ). Lean body mass ( $\pm \mathrm{SE}$ ) increased in the verum group from $52 \pm 1.9$ to $56.6 \pm 2 \mathrm{~kg}$ $(P<0.01)$, but remained constant in the placebo group (from $47 \pm 3.9$ to $49.9 \perp 3.1 \mathrm{~kg})$.

Maximal oxygen consumption ( $\mathrm{VO}_{2}$ max), maximal $\mathrm{O}_{2}$ pulse, exercise time, anaerobic threshold, and maximal power output. The $\mathrm{VO}_{2} \max ( \pm \mathrm{SE})$ increased significantly from $1.9 \pm 0.2$ to $2.6 \pm 0.18 \mathrm{~L} / \mathrm{min}(P<0.01)$ in the group treated with $\mathrm{hGH}$, whereas in the placebo group, no significant changes (from $1.9 \pm 0.18$ to $2.2 \pm 0.18 \mathrm{~L} / \mathrm{min}$ ) could be detected.

The data, expressed per $\mathrm{kg} \mathrm{BW}( \pm \mathrm{SE})$ showed a significant increase in $\mathrm{VO}_{2}$ max from $23.2 \pm 2.4$ to $30 \pm 2.3 \mathrm{~L} / \mathrm{min} \cdot \mathrm{kg}$ $\mathrm{BW}(P<0.005)$ after a 6-month GH treatment period in the verum group, but there was no significant increase in the placebo group (from $22.2 \pm 1.9$ to $25.6 \pm 2.0$ ). When expressed as a percentage of the expected value, the $\mathrm{VO}_{2} \max$ 
per $\mathrm{kg}$ BW increased significantly in the verum group from $81.8 \pm 10.2 \%$ to $110.8 \pm 7.9 \%(P<0.005)$, but showed no significant increase in the placebo group (from $84.6 \pm 5.9 \%$ to $98.1 \pm 8.1 \%$; Fig. 1).

Maximal $\mathrm{O}_{2}$ pulse ( \pm SE) increased significantly from $15.2 \pm 5.6$ to $19.6 \pm 3.3 \mathrm{~mL} /$ beat $(P<0.01$ in the hGH-trealed group), but remained constant in the placebo group (14.3 \pm 1.2 to $16.3 \pm 1.1 \mathrm{~mL} /$ beat; Fig. 1 ).

The $\mathrm{VO}_{2}$ max data, expressed per kg lean body mass did not change significantly in either group (hGH, from $39.8 \pm$ 9.4 to $44.1 \pm 6.6 \mathrm{~mL} / \mathrm{min} \cdot \mathrm{kg}$; placebo, from $41.4 \pm 16.8$ to $44.8 \pm 11.2 \mathrm{~mL} / \mathrm{min} \cdot \mathrm{kg}$ ).

The maximal power output ( $\pm \mathrm{sE}$ ) achievable by the patients increased significantly from $192.5 \pm 13.5$ to $227.5 \pm 11.5$ watts $(P<0.01)$ after 6 months in the verum group, bul
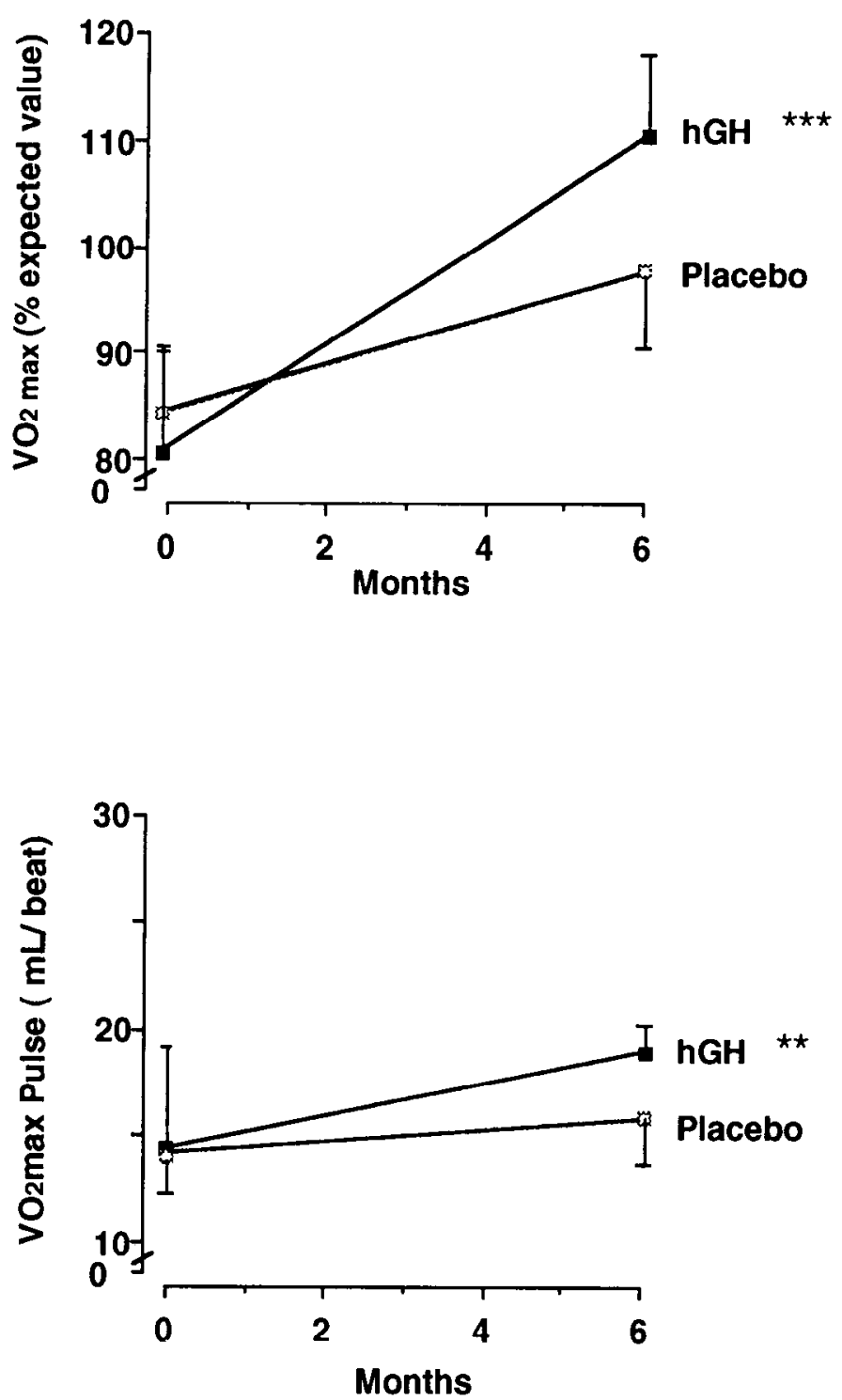

FIG. 1. Changes in maximal $\mathrm{O}_{2}$ uptake, expressed as a percentage of the expected value (top) and changes in maximal $\mathrm{O}_{2}$ pulse (bottom) after GH treatment (closed symbols) or placebo (open symbols). Values are the mean $\pm \mathrm{SE}$. No significant differences existed between groups at baseline: **, $P<0.01 ; * * * *, P<0.005$. showed no significant changes (from $187.5 \pm 16.8$ to $192.5 \pm$ 14.9 watts) in the placebo group (Fig. 2).

The same result was found when the power output data were expressed per $\mathrm{kg} \mathrm{BW}[\mathrm{hGH}, 2.2 \pm 0.17$ and $2.4 \pm 0.18$ $(P<0.01)$; placebo, $2.1 \pm 0.19$ and $2.1 \pm 0.13$ at 0 and 6 months, respectively]. When the data were expressed as watts per $\mathrm{kg}$ lean body mass, no significant change could be detected in either group (hGH, $3.7 \pm 0.3$ and $3.5 \pm 0.3$; placebo, $3.8 \pm 0.2$ and $3.8 \pm 0.1$ at 0 and 6 months, respectively; Table 2).

The exercise time ( $\pm \mathrm{SE}$ ) sustained and, thereby, the total work performed by the patients under the protocol specified in Materials and Methods increased significantly in the verum group from $6.35 \pm 0.6$ to $6.77 \pm 0.5$ watts $(P<0.05)$, whereas there were no significant changes in the placebo group (from $6.05 \pm 0.7$ to $6.17 \pm 0.6$ ).

The product of power output and operating time (watts $x$ min \pm SE) showed a significant increase in the verum group from $1274.4 \pm 201$ to $1439.1 \pm 198(P<0.05)$ after 6 months of treatment, whereas in the placebo group, no significant change (from $1182 \pm 204.9$ to $1212.6 \pm 197$ ) was found.

The maximal ventilation $( \pm \mathrm{SE})$ increased significantly in the verum group from $53.4 \pm 6.3$ to $59.4 \pm 6.0 \mathrm{~L} / \mathrm{min}(P<$ 0.05 ), whereas in the placebo group, no significant changes could be observed (from $50.5 \pm 5.3$ to $53.9 \pm 5.7 \mathrm{~L} / \mathrm{min}$; Table 2).

Changes in the anaerobic threshold, expressed per kg BW, showed the same results. The anaerobic threshold $( \pm \mathrm{SE})$ increased in the hGH group significantly from $16.88 \pm 1.8$ to $20.44 \pm 1.7 \mathrm{~mL} / \mathrm{min} \cdot \mathrm{kg}(P<0.01)$ as well as in the placebo group, where we found a smaller, but significant, increase from $16.04 \pm 1.0$ to $18.42 \pm 1.2 \mathrm{~mL} / \mathrm{min} \cdot \mathrm{kg}(P<0.05)$.

\section{Cardiac parameters und blood pressure}

Before treatment, no patient had values for wall thicknesses or chamber dimension outside the adult reference range of our clinic. After the 6 months of treatment, no significant changes were noted concerning the measured left ventricular posterior wall, left atrium, or interventricular septum thickness or the LVESD, LVEDD, or fractional short-

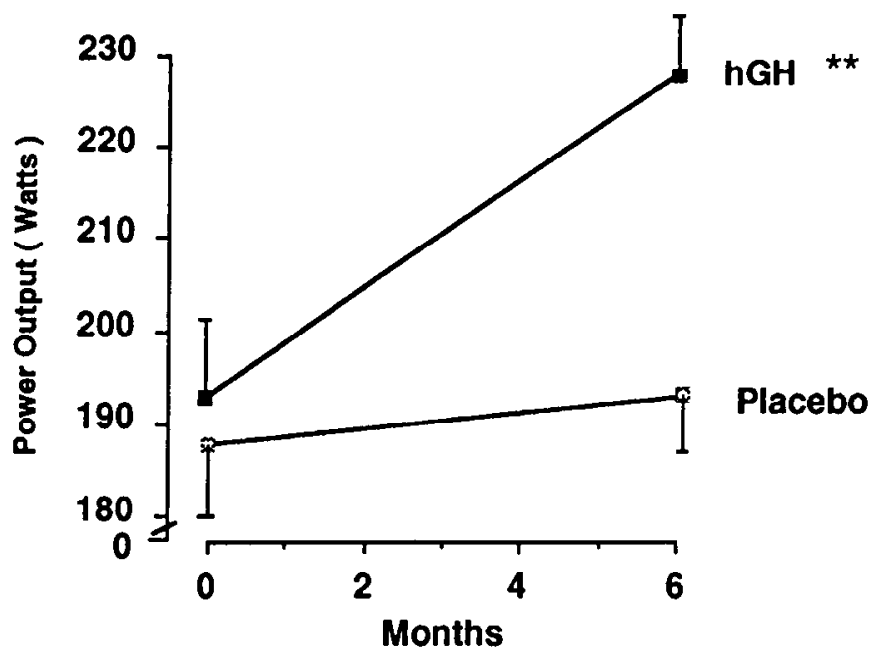

Frr. 2. Changes in maximal power output after GH treatment (closed symbols) or placebo (open symbols). No significant differences existed between groups at baseline: **, $P<0.01$. 
TABLE 2. Maximal ventilation, anaerobic threshold, maximal power output

\begin{tabular}{|c|c|c|c|}
\hline Treatment & Baseline & 6 months & $P$ \\
\hline \multicolumn{4}{|c|}{ Maximal ventilation $(\mathrm{L} / \mathrm{min})$} \\
\hline rhGH & $53.4 \pm 6.3$ & $59.4 \pm 6.0$ & $<0.05$ \\
\hline Placebo & $50.5 \pm 5.3$ & $53.9 \pm 5.7$ & NS \\
\hline \multicolumn{4}{|c|}{$\begin{array}{l}\text { Anaerobic threshold } / \mathrm{kg} \text { BW } \\
(\mathrm{mL} / \mathrm{min} \cdot \mathrm{kg})\end{array}$} \\
\hline $\mathrm{rhGH}$ & $16.9 \pm 1.8$ & $20.4 \pm 1.7$ & $<0.01$ \\
\hline Placebo & $16.04 \pm 1.0$ & $18.4 \pm 1.2$ & 0.05 \\
\hline \multicolumn{4}{|c|}{$\begin{array}{l}\text { Maximal power output } \\
\text { (watts) }\end{array}$} \\
\hline rhGH & $192.5 \pm 13.5$ & $227.5 \pm 11.5$ & $<0.01$ \\
\hline Placebo & $187.5 \pm 16.8$ & $192.5 \pm 14.9$ & NS \\
\hline \multicolumn{4}{|c|}{$\begin{array}{l}\text { Maximal power output BW } \\
\text { (watts } / \mathrm{kg} \text { ) }\end{array}$} \\
\hline rhGH & $2.2 \pm 0.17$ & $2.4 \pm 0.18$ & $<0.01$ \\
\hline Placebo & $2.1 \pm 0.19$ & $2.1 \pm 0.13$ & NS \\
\hline \multicolumn{4}{|c|}{$\begin{array}{c}\text { Maximal power output/lean } \\
\text { body mass (watts } / \mathrm{kg} \text { ) }\end{array}$} \\
\hline rhGH & $3.7 \pm 0.3$ & $3.5 \pm 0.3$ & NS \\
\hline Placebo & $3.8 \pm 0.2$ & $3.8 \pm 0.1$ & NS \\
\hline \multicolumn{4}{|l|}{ Exercise time $(\min )$} \\
\hline rhGH & $6.35 \pm 0.6$ & $6.77 \pm 0.5$ & $<0.05$ \\
\hline Placebo & $6.05 \pm 0.7$ & $6.17 \pm 0.6$ & NS \\
\hline
\end{tabular}

Values are the mean \pm SE. No significant differences existed between groups at baseline.

TABLE 3. Echocardiographic results

\begin{tabular}{|c|c|c|c|}
\hline Treatment & Baseline & 6 months & $P$ \\
\hline \multicolumn{4}{|l|}{ IVS (mm) } \\
\hline rhGH & $9.3 \pm 1.1$ & $9.3 \pm 1.1$ & NS \\
\hline Placebo & $9.3 \pm 0.7$ & $9.6 \pm 0.6$ & NS \\
\hline \multicolumn{4}{|l|}{ LVPW (mm) } \\
\hline rhGH & $8.0 \pm 0.8$ & $8.3 \pm 0.8$ & NS \\
\hline Placebo & $8.0 \pm 0.6$ & $8.6 \pm 0.5$ & NS \\
\hline \multicolumn{4}{|l|}{ LV-ESD (mm) } \\
\hline rhGH & $31.8 \pm 1.2$ & $32.3 \pm 1.1$ & NS \\
\hline Placebo & $31.7 \pm 2.2$ & $31.1 \pm 2.1$ & NS \\
\hline \multicolumn{4}{|l|}{ LV-EDD (mm) } \\
\hline rhGH & $48.7 \pm 1.5$ & $49.2 \pm 1.5$ & NS \\
\hline Placebo & $48.9 \pm 2.7$ & $48.9 \pm 2.1$ & NS \\
\hline \multicolumn{4}{|l|}{ FS $(\%)$} \\
\hline rhGH & $35.3 \pm 0.8$ & $35.2 \pm 1.0$ & NS \\
\hline Placebo & $35.7 \pm 1.5$ & $36.7 \pm 1.7$ & NS \\
\hline \multicolumn{4}{|l|}{ LVM $(g)$} \\
\hline $\mathrm{rhGH}$ & $148.1 \pm 24.5$ & $153.9 \pm 25.2$ & NS \\
\hline Placebo & $158.9 \pm 30.3$ & $156.4 \pm 17.2$ & NS \\
\hline \multicolumn{4}{|l|}{$\mathrm{LA}(\mathrm{mm})$} \\
\hline rhGH & $38.0 \pm 0.8$ & $37.8 \pm 1.1$ & NS \\
\hline Placebo & $38.5 \pm 0.8$ & $39.5 \pm 0.9$ & NS \\
\hline \multicolumn{4}{|c|}{ LVM/body surface area $\left(\mathrm{g} / \mathrm{m}^{2}\right)$} \\
\hline rhGH & $73.8 \pm 9.7$ & $77.2 \pm 10.8$ & 0.058 \\
\hline Placebo & $63.1 \pm 6.7$ & $66.7 \pm 6.6$ & NS \\
\hline
\end{tabular}

Values are the mean $\pm \mathrm{SE}$. No significant differences existed between groups at baseline. $P<0.05$ was considered significant. LVM/ body surface area shows a trend to increase during hGH replacement therapy. IVS, interventricular septum; I.VPW, left ventricular posterior wall; LV-ESD, left ventricular end-systolic dimension; LVEDD, left ventricular end-diastolic dimension; FS, fractional shortening; LVM, left ventricular mass; LA, left atrium.

ening (FS; Table 3). LVM ( \pm SE) increased slightly, but not statistically significantly, from $148.1 \pm 24.5$ to $153.9 \pm 25.2 \mathrm{~g}$. When expressed as LVM per body surface area, we found a tendency $(P=0.058)$ to higher values only in the verum group after 6 months of treatment (from $73.8 \pm 9.7$ to $77.2 \pm$
$10.8 \mathrm{~g} / \mathrm{m}^{2}$ ). It should be noted that in only $60 \%$ of the patients was a reliable echocardiographic result obtained, because of technical difficulties due to the high BMI of the patients. The maximal systolic (from $188.6 \pm 9.3$ to $194 \pm 14.2 \mathrm{~mm} \mathrm{Hg}$ ) and diastolic (from $105 \pm 5.5$ to $104.7 \pm 5.4 \mathrm{~mm} \mathrm{Hg}$ ) blood pressures as well as the maximal heart rate (from $140.9 \pm 5.8$ to $144 \pm 6.9$ beats $/ \mathrm{min}$ ) showed no significant change in either group after 6 months of hGH treatment.

Side-effects. Transient side-effects were observed only in the verum group in four patients, during the first 6 weeks of treatment. All four patients developed edema. Three of these four patients also reported muscle pain, and two of them fatigue. In two patients, the hGH dose was reduced to 6.25 $\mu \mathrm{g} / \mathrm{kg} \mathrm{BW} \cdot$ day, and in all patients, the side-effects dissolved within 3-6 weeks.

\section{Discussion}

Over the 6-month period of hGH replacement, IGF-I levels increased in 10 patients with proven hGH deficiency, but remained constant in the 10 placebo-treated patients. Our findings of an increase of $5 \mathrm{~kg}$ in lean body mass, as assessed by potassium- 40 counting, is in good agreement with previous reports (5). This increase in lean body mass reflects, in particular, muscle mass. Studies in normal subjects (14) have shown that $\mathrm{GH}$ increases muscle protein synthesis, as also demonstrated by the St. Thomas group (15). Joergensen $e t$ al. (16) reporled that the increase in lean body mass is combined with an increase in isometric muscle strength.

Little is known concerning the effects of hGH replacement therapy on static and maximal respiratory function. Initial studies (17-19) could not detect an effect of hGH on these parameters.

Furthermore, our data show that GH deficiency in adults is associated with a decrease in the pulmonary parameters measured by spiroergometry compared to those in a reference population (20), and parameters reverted to normal during hGH replacement. Especially the data for $\mathrm{VO}_{2}$ max per kg BW increased from levels below the normal range to even slightly above the normal range, and this increase in $\mathrm{VO}_{2}$ max was associated with improved power output.

The improvement in $\mathrm{VO}_{2}$ max was even more pronounced when corrected for total body weight. When related to lean body mass, however, no alterations in $\mathrm{VO}_{2}$ max could be demonstrated in either group. These results underline the fact that the increase in lean body mass is an important factor for the improvement of $\mathrm{VO}_{2} \max (21)$, especially as the $\mathrm{VO}_{2}$ max during maximal exercise occurs almost exclusively in the exercising muscles as blood is shunted away from the splanchnic bed (22).

According to the data of Joergensen et al. (16), the increase in lean body mass especially reflects an increase in muscle tissue and, therefore, might result in an increase in respiratory muscle strength. The fact that we could find an increase in the maximal ventilation volume supports the assumption that the increase in respiratory muscle strength during hGH treatment might partially influence the maximal oxygen uptake. 'The changes during hGH treatment in muscle volume per se might play an important role in the changes in $\mathrm{VO}_{2}$ 
max. In this context, it is interesting to note that Fleg and Laketta (23) showed that the age-related muscle loss is associated with a progressive decline in $\mathrm{VO}_{2}$ max.

As our patients received adequate and constant hormone replacement therapy with $\mathrm{T}_{4}$, glucocorticoids, and gonadal steroids for 12 months before and during the trial, we conclude that the changes observed are not influenced by the standard replacement therapy, especially the glucocorticoid or testosterone therapy in male patients, but are caused by hGH. Our patients were advised not to change their diets or daily activities, but they were not restricted in this respect. The analysis of the daily activity questionnaires showed no significant increase in daily activity during the 6 months of treatment in either group. During the 6-month treatment period, the patients reported no change in daily diet.

It is our opinion that both direct metabolic effects of $\mathrm{hGH}$ as well as possible indirect psychological effects (24), leading to increased physical activity, may have contributed to the increase in power output. The anaerobic threshold showed a significant increase in both groups, but with a higher increment in the hGH-treated group. The remarkable increase in the anaerobic threshold, especially in the verum group, might be due to the improved oxygen consumption under hGH replacement.

The increase in the $\mathrm{O}_{2}$ pulse in the group treated with hGH underlines the positive effect of hGH on the cardio-pulmonary exercise performance and might contribute to the improvement in exercise capacity during hGH treatment. The fact that the maximal $\mathrm{O}_{2}$ pulse increased significantly during hGH treatment could be explained by an increased cardiac output under the assumption that arterio-venous $\mathrm{O}_{2}$ content is not altered by hGH treatment, an idea that requires confirmation. This is an indirect conclusion, as we did not measure the arterio-venous $\mathrm{O}_{2}$ content difference. Our data show a significant increase in oxygen uptake per heartbeat under hGH treatment, and this effect might be due to increased peripheral oxygen consumption or might be explained by an increased cardiac output and, therefore, reflects an increased stroke volume.

The assumption that $\mathrm{GH}$ increases cardiac output in $\mathrm{GH}$ deficient patients is supported by the findings of Merola et al. (25), who described a decreased ejection fraction in GHdeficient adults. Furthermore, Cuneo et al.(26) could show in one case the increase in cardiac output in a patient with dilated cardiomyopathy, and Thuesen et al. (27) showed an increase in cardiac output in normal subjects during hGH treatment. We, therefore, examined cardiac structure by echocardiography.

In contrast to previous results, we could not detect any significant changes measured by echocardiography concerning either the cardiac function or the cardiac structure of our patients. The only changes were a slight, but not significant, increase in the LVM, as expressed per body surface area. Cuneo and co-workers (8) described an increase in left ventricular myocardial mass after 6 months of hGH treatment of $\mathrm{GH}$-deficient adults as well as an increase in stroke volume. The other parameters (LVESD, FS, and wall thickness) showed no significant differences after hGH treatment. The discrepancy between our data and those of Cuneo et al. (8) might be explained by the lower hGH dosage used in our study. This suggestion is supported by the data from the Aarhus group (16), who could not detect any changes in the left ventricular wall mass using a hGH dosage comparable to that we used.

According to Cuneo et al. (28), the increase in stroke volume after hGH treatment may reflect increased preload (Starling effect) due to the sodium-retaining effect of $\mathrm{hGH}$, which results in an increased circulating blood volume. It appears that in our study this effect played a minor role, as LVEDD determined by echocardiography did not increase during hGH treatment.

Furthermore, it is important to note that left ventricular dimensions and wall thicknesses were within normal limits before and after treatment in our study group. According to these data, we conclude that hCH in physiological replacement dosage does not change cardiac structure and seems not to affect myocardial structure, as observed in acromegaly (29). Concerning cardiac function, on the other hand, according to our $\mathrm{O}_{2}$ pulse data, hGH might increase stroke volume, a fact that has been reported previously by others (26). We cannot comment on this observation by using echocardiographic measurements, because we do not consider the FS determined echocardiographically to be a reliable parameter for stroke volume.

The observation that hGH does not change the cardiac structure, but does affect cardiac stroke volume, might be explained by the fact that hGH therapy also alters the muscle fiber metabolism (30). Furthermore, the increase in $\mathrm{VO}_{2}$ max and in the anaerobic threshold during hGH therapy might be influenced by changes in energy metabolism.

Press (31) showed that GH enhances carbohydrate metabolism and muscle and hepatic glycogen stores. Lipid metabolism seems to play no role in the increase in exercise performance $(32,33)$.

To our knowledge, no data exist concerning changes in the oxygen transport capacity of erythrocytes during hGH therapy. We did not detect changes in the whole erythrocyte mass in either group (data not shown), and this parameter seems to play a minor role in the observed improvement in $\mathrm{VO}_{2} \max$.

The highly significant increases in the exercise time and power output suggest that the beneficial effects of hGH treatment on pulmonary parameters $\left(\mathrm{VO}_{2} \max\right.$ and anaerobic threshold) improve physical work capacity. It is, therefore, conceivable that tasks of every day life can be performed by the patients with more ease.

In summary, according to our data, adults with $\mathrm{GH}$ deficiency acquired in adulthood show decreased $\mathrm{VO}_{2}$ max compared to that in a reference population, which can be normalized by hGH replacement therapy. Furthermore, during hGH treatment, we found a significant increase in lean body mass. After 6 months of trealment with hGH, exercise performance, as well as $\mathrm{VO}_{2}$ max, anaerobic threshold, and $\mathrm{O}_{2}$ pulse improved significantly. Cardiac structure showed no significant changes during our low dosage hGH replacement regimen, whereas functional improvements, probably due to improved muscle metabolism, might contribute to the improved exercise performance.

As the increase in lean body mass in our study parallels the improvement in $\mathrm{VO}_{2}$ max and exercise performance, we 
conclude that the increase in muscle mass is a major reason for these observations. Investigations over longer study periods are mandatory to arrive at further conclusions concerning the effects of hGH in adults on body composition and exercise performance, especially with respect to possible adverse long term effects, which were not observed in this study.

\section{Acknowledgments}

The authors wish to thank Dr. A. Attanasio (Lilly Research Center, Erl Wood, United Kingdom) for valuable discussion, Dr. A. König (Medical Clinic, Innenstadt University Hospital, Munich, Germany) for statistical advice, and Ms. K. Schriever for expert technical assistance.

\section{References}

1. Thorner MO, Vance ML. 1988 Growth hormone. J Clin Invest. 82:745-747.

2. Corpas E, Harman SM, Blackman MR. 1993 Human growth hormone and human aging. Endocr Rev, 14:20-39.

3. Tanner JM, Hughes PCR, Whitehouse RH. 1977 Comparative rapidity of response of height, limb muscle and limb fat to treatment with human growth hormone in patients with and without growth hormone deficiency. Acta Endocrinol (Copenh). 84:681-689.

4. Rutherford OM, Jones DA, Round JM, Buchanan CR, Preece MA. 1991 Changes in skeletal muscle and body composition after discontinuation of growth hormone treatment in growth hormone deficient young adults. Clin Endocrinol (Oxf). 34:467-475.

5. Salomon F, Ross CC, Hesp R, Sönksen P. 1989 The effects of treatment with recombinant human growth hormone on body composition and metabolism in adults with growth hormone deficiency. N Engl J Med. 321:1797-1803.

6. Bengtsson BA, Edn S, Lönn L. 1993 Treatment of adults with growth hormone $(\mathrm{GH})$ deficiency with recombinant human $\mathrm{GH}$. J Clin Endocrinol Metab. 76:309-317.

7. Vance ML. 1990 Growth hormone for elderly? N Engl J Med. 323: $52-54$.

8. Cuneo RC, Salomon F, Wilmshurst P, et al. 1991 Cardiovascular effects of growth hormone treatment in growth-hormone-deficient adults: stimulation of the renin-aldosterone system. Clin Sci. 81: $587-592$.

9. Blum WF, Gallagher B, Ranke MB. An IGFBP-blocked IGF-I RIA that measures what it pretends to measure: IGF-I. Proc of the 74th Annual Meet of The Endocrine Soc. 1992;293.

10. Smith T, Hesp R, Mackenzie J. 1979 Total body potassium calibration for normal and obese subjects in two types of whole body counter. Phys Med Biol. 24:171-175.

11. Womersely J, Boddy K, King PC, Durnin JV. 1972 A comparison of the fat-free mass of young adults estimated by anthropometry, body density and total body potassium content. Clin Sci. 43:469-475.

12. Sahn DJ, DeMaria AN, Kisslo J, Weyman A. 1978 Recommendations regarding quantitation in M-mode echocardiography: results of a survey of echocardiographic measurements. Circulation. 58: $1072-1083$.

13. Devereux RB, Alonso DR, Lutas EM, et al. 1986 Echocardiographic assessment of left ventricular hypertrophy: comparison to necropsy findings. Am J Cardiol. 57:450-458.
14. Fryburg DA, Gelfand RA, Barrett EJ. 1991 Growth hormone acutely stimulates forearm muscle protein synthesis in normal humans. Am J Physiol. 260:499-504.

15. Russell-Jones DL, Weissberger AJ, Bowes SB, et al. 1993 Protein metabolism in growth hormone deficiency, and effects of growth hormone replacement therapy. Acta Endocrinol (Copenh). 128(Suppl 2):44-47.

16. Joergensen JO, Pedersen SA, Thuesen L. 1989 Beneficial effects of growth hormone treatment in GH-deficient adults. Lancet 1:12211225.

17. Cuneo RC, Salomon F, Wiles CM, Hesp R, Sönksen PH. 1991 Growth hormone treatment in growth hormone-deficient adults. II. Effects on exercise performance. J Appl Physiol. 70:65-700.

18. Longobardi S, Merola B, Colao A, et al. 1994 Failure of ventilatory function in GH deficiency (GHD). Endocrinol Metab 1(Suppl B):158.

19. Suchner U, Rothkopf MM, Stanislaus G, Elwyn DH, Kvetan V, Askanazi J. 1990, Growth hormone and pulmonary disease. Metabolic effects in patients receiving parenteral nutrition. Arch Intern Med. 150:1225-1230.

20. Rühle KH, Fischer J, Matthys H. 1983 Sollwerte für die Spiroergometrie. Atem Lungenkrankheit. 9:157-173.

21. Shepard RJ, Bouhlel E, Vandewalle H, Monod H. 1988 Muscle mass as a factor limiting physical work. J Appl Physiol. 64:1472-1479.

22. Clausen, JP. 1969 Effects of physical conditioning. A hypothesis concerning circulatory adjustments to exercise. Scand J Clin Lab Invest. 24:305-311.

23. Fleg JL, Lakatta EG. 1988 Role of muscle loss in the age-associated reduction in $\mathrm{VO}_{2}$ max. J Appl Physiol. 65:1147-1151.

24. McGauley GA. 1989 Quality of life assessement before and after growth hormone treatment in adults with growth hormone deficiency. Acta Paediatr Scand. 356(Suppl):70-72.

25. Merola B, Cittadini A, Colao A, et al. 1993 Cardiac, structural, and functional abnormalities in adult patients with growth hormone deficiency. J Clin Endocrinol Metab. 77:1658-1661.

26. Cuneo RC, Wilmshurst P, Lowy C, McGauley G, Sönksen PH. 1989 Cardiac failure responding to growth hormone. Lancet. 1:838-839.

27. Thuesen L, Christiansen JS, Sorensen KE, Jorgensen JOL, Orskov H, Heningsen P. 1988 Increased myocardial contractility following growth hormone administration in normal man. Dan Med Bull. 35:193-196

28. Cuneo RC, Salomon F, Wilmshurst P, et al. 1991 Cardiovascular effects of growth hormone treatment in growth-hormone-deficient adults: stimulation of the renin-aldosterone system. Clin Sci. 81: $587-592$.

29. Bengtsson B, Eden S, Ernest I, Oden A, Sjögren B. 1988 Epidemiology and long term survival in acromegaly. Acta Med Scand. 22.3: 237-235.

30. Zorzano A, James DE, Ruderman NB, Pilch PF. 1988 Insulin-like growth factor 1 binding and receptor kinase in red and white muscle. FEBS Lett. 234:257-262.

31. Press M. Growth hormone and metabolism. 1988 Diabetes Metab Rev, 4:391-414.

32. Crist DM, Peake GT, Loftfield RB, Kraner JC, Egan PA. 1991 Supplemental growth hormone alters body composition, muscle protein metabolism and serum lipids in fit adults: characterization of dose-dependent and response-recovery effects. Mech Ageing Dev. 58:191-205.

33. Bonnet $F$, Vanderschueren-Lodeweyckx $M$, Eeckels $R$, Malvaux $P$. 1974 Subcutaneous adipose tissue and lipids in blood in growth hormone deficiency before and after treatment with human growth hormone. Pediatr Res. 8:800-805. 